Journal of Marine Systems

April 2016, Volume 156, Pages 46-55

http://dx.doi.org/10.1016/i.jmarsys.2015.12.002

http://archimer.ifremer.fr/doc/00302/41339/

(c) 2015 Elsevier B.V. All rights reserved

\title{
Response of the Southern Benguela upwelling system to fine-scale modifications of the coastal wind
}

\author{
Desbiolles Fabien ${ }^{1,}{ }^{*}$, Blanke Bruno ${ }^{1}$, Bentamy Abderrahim ${ }^{2}$, Roy C. ${ }^{1}$ \\ ${ }^{1}$ Laboratoire de Physique des Océans (LPO), UMR 6523 CNRS-Ifremer-IRD-UBO, Brest, France \\ ${ }^{2}$ Laboratoire d'Océanographie Spatiale (LOS), Ifremer, centre de Brest, France \\ * Corresponding author : Fabien Desbiolles, email address : $\underline{\text { fabien.desbiolles@univ-brest.fr }}$
}

\begin{abstract}
:
We analyze the results of a regional model of the Southern Benguela upwelling system forced by wind stress fields derived from QuikSCAT observations. Two different horizontal resolutions are considered for the wind stress: QS25 and QS50, corresponding to native 25 and $50 \mathrm{~km}$ grids, respectively. The differences between both products highlight the primary importance of fine-scale momentum fluxes for both the structure and intensity of the wind- and wind curl-driven upwelling. Using QS25, we show that the coastal Ekman transport is reduced, leading to a warmer SST and a reduced oceanic coastal jet. QS25 finer wind stress curl patterns also favor the development of a stronger and shallower poleward undercurrent. The addition of a coastal wind correction to QS25 lets us investigate the possible implications of an imbalance between Ekman transport and Ekman pumping: a wind reduction in the coastal band often reduces the SST cooling, but the two mechanisms compensate each other when the characteristic length scales of the coastal upwelling and the orography-induced wind drop-off are similar.
\end{abstract}

\section{Highlights}

- Southern Benguela Upwelling dynamics related to atmospheric fine-scales. Use of new scatterometer data to force a hydrodynamic model at the surface. Short-term response of the ocean to a unique change of momentum fluxes. The fate of the coastal Southern Benguela waters using numerical Lagrangian experiments. Impact of wind drop-off on both vertical structures and crossshore exchanges of particles.

Keywords: Eastern boundary upwelling system, momentum flux forcing, wind profile, numerical modeling, scatterometry 


\section{Introduction}

Several studies have shown the primary importance and the combined effect of wind- and wind curl-driven upwelling dynamics in the eastern boundary upwelling systems (EBUS) [e.g., Capet at al, 2004]. Specifically, the oceanic heat balance, vertical mixing and geostrophic adjustment can be related to the spatial and temporal variability of the surface momentum fluxes [Renault et al., 2009, 2012; Colas et al., 2012]. Indeed, wind stress plays a dominant role in determining Ekman transport and coastal upwelling and thus in forcing the sea surface temperature (SST) distribution and shaping the full three-dimensional ocean circulation over the continental shelf [Fennel et al., 2012]. The wind stress curl (WSC) controls Ekman pumping and, thus, modulates vertical advection [Chelton, 1982].

In the Benguela system, like in the other EBUSs (i.e., Canary, Humboldt and California), the spatial and temporal structure of the upwelling is mainly driven by the coastal wind variability. Cross-shore variations of the wind have received considerable attention since they modify both the coastal and basin-scale circulation linked to upwelling dynamics [Marchesiello et al., 2003; Capet et al., 2004; Rykaczewski and Checkley; 2008; Albert et al., 2010]. Various processes can produce fine spatial and temporal wind scales, which often results in a wind reduction in the nearshore region of EBUSs, the so-called wind drop-off (i.e., Capet et al. [2004], Perlin et al. [2007] and Renault et al. [2015] for the California system; Renault et al. [2012] for the Humboldt system; Desbiolles et al. [2014b] for both the Benguela and Canary systems). As reported and quantified in Renault et al. [2015], physical processes linked to coastal orography [Edwards et al., 2001], the presence of a cape [Perlin et al., 2011], SST-wind interactions [Chelton et al., 2007] and sharp changes in surface drag at the sea-land interface [Edwards et al., 2001] are involved in the modification of the coastal winds.

More specifically, the SST distribution, reflecting both the Ekman-induced cross-shore temperature gradient and the mesoscale characteristics of the upwelling dynamics, feeds back on the 
marine atmospheric boundary layer through turbulent vertical mixing and convection [Song et al., 2009]. This generates small-scale features in the low-level wind [Chelton et al., 2004; O'Neill et al., 2005, Small et al., 2008]. In a previous study, we showed that the coupling between wind and SST is the main driver of both the magnitude and the variability of the wind stress curl during the upwelling season in the Benguela and Canary systems [Desbiolles et al., 2014b]. SST-driven modifications to the wind contribute to a wind reduction in a transition region that may extend over $100 \mathrm{~km}$ offshore [Boé et al., 2011]. When approaching the coast, other perturbations induced by orography, by a rugged coastal landscape or by changes in the value of the drag coefficient become progressively more important, complicating the structure of the wind stress curl. Specifically, Renault et al. [2015] stressed that the orographic effect is the primary contributor to wind drop-off in the nearshore ocean (with up to a $30 \%$ reduction over a $20-25 \mathrm{~km}$ coastal strip for the highest coastal orography in California).

It has been shown that the use of synoptic scales in the atmospheric momentum fluxes substantially improves the ability of numerical models to reproduce the observed SST variability in the Southern Benguela system [Blanke et al., 2002; 2005]. The physical forcing plays a crucial role in determining the full hydrodynamic of EBUS and impacts on the whole ecosystem, from the lower to the upper trophic levels [Hutchings et al., 1998; Blamey et al., 2015]. Considering the amount of daily wind stress products available with increasingly finer horizontal scales, this study aims at highlighting the short-term response of the ocean to a simple change of momentum fluxes in a hydrodynamic model. Specifically, we use the last QuikSCAT-derived wind products processed at Ifremer (Institut Français de Recherche pour 1'Exploitation de la Mer) to document and quantify the effect of small-scale wind stress structures on the Southern Benguela dynamics. The products used in this study mainly differ in the representation of SST-wind interactions (see section 2.2). A blind zone in scatterometer coverage (a few tens of kilometers from the coast) is still a strong limitation over the inner shelf since regional ocean models are now run at high resolution (a few kilometers), thus with ocean grid cells lying in this blind zone. Several options are available to fill the wind data 
gaps in this zone. Here, we investigate the impact that an orography-induced coastal wind reduction would have on both the ocean vertical structure and the cross-shore exchange of particles, and we especially quantify the antagonistic effects of an increase in Ekman pumping and a reduction in Ekman transport.

\section{Models and set of experiments}

\subsection{Eulerian and Lagrangian models}

The model configuration and run setups are similar to the ones described in Desbiolles et al. [2014a]. We use the split-explicit, free-surface, primitive equations Regional Ocean Modeling System (ROMS), based on the Boussinesq approximation and hydrostatic vertical momentum balance [Shchepetkin and McWilliams, 2005, 2009]. The domain covers the ocean around Southern Africa from $38^{\circ} \mathrm{S}$ to $20^{\circ} \mathrm{S}$ and from $5^{\circ} \mathrm{E}$ to $22^{\circ} \mathrm{E}$. The spatial resolution is $1 / 12^{\circ}$ with 32 terrainfollowing vertical levels (with a higher resolution in the upper ocean layer). The bottom topography is derived from the ETOPO2 (2' resolution) data set [Smith and Sandwell, 1997]. The simulation is initiated from rest and forced at its lateral open boundaries with temperature, salinity and velocity fields obtained from the monthly World Ocean Atlas 2005 climatology [Antonov et al., 2006; Locarnini et al., 2006]. The model is forced by fresh water and heat fluxes extracted from the Comprehensive Ocean-atmosphere Data Set (COADS) ocean surface monthly climatology at $1 / 2^{\circ}$ resolution. The small size of the domain and the use of climatological fields as constraints on the model open boundaries prevent the accurate reproduction of the variability that can be observed over the continental shelf with remotely sensed and in situ data. However, the numerical configuration is suitable for process-oriented studies based on sensitivity to the local atmospheric forcing [Desbiolles et al., 2014a]. The Lagrangian analyses are based on the offline ARIANE algorithm [Blanke and Raynaud, 1997; Blanke et al., 1999], here used to diagnose the fate of coastal particles and to quantify integrated volume transports between key vertical sections across the 
domain.

\subsection{Wind stress forcing and set of numerical experiments}

This study uses wind retrievals from the SeaWinds scatterometer on board QuikSCAT (a complete description of this instrument can be found in JPL [2006]). All quality controls relying on quality flags associated with the L2b product (wind retrievals) are used for wind data selection. Level 2 data have been significantly improved in the coastal band, which allowed reduction of the blind zone off the coast to approximately $12.5 \mathrm{~km}$ [Stiles, 2014]. These data are used to estimate winds on a regular grid of $0.25^{\circ}$ in longitude and latitude (hereafter QS25). The latest developments of the Ifremer team are detailed in Bentamy et al. [2011, 2013]. The QS25 wind stress field is extrapolated toward the coast to fill the blind zone in scatterometer coverage, and then interpolated to the model grid. Specifically, the extrapolation is based on the use of the closest neighboring values and the method of interpolation is bilinear. The numerical experiment run with this wind product will be considered as the reference (qs25).

We set up another numerical experiment with a slightly altered wind stress field. It only differs from QS25 by a modification of the coastal winds (QS25 mod hereafter). Specifically, we complete coastal gaps in QS25 with zonal gradients derived from ECMWF (European Center for Medium-Range Weather Forecasts) reanalysis data: daily means of the wind stress are based on the analyses at 00:00, 06:00, 12:00, and 18:00 UTC from the Integrated Forecasting System (IFS) operational global atmospheric model. This model was run with a grid size of approximately $40 \mathrm{~km}$ and assimilated satellite-derived wind data, and especially QuikSCAT observations, during our period of study (2005), and these data are provided by the european center. The ECMWF correction, more precisely the local and daily zonal gradient in the ECMWF meridional stress component, is applied from the first (westernmost) missing grid cell in the nominal QS25 product. This gradient is extended eastward, without yet accepting a reversal of the component (in which case, the meridional wind stress is maintained at zero). When they first used this wind correction 
over the coastal blind zone, Desbiolles et al. [2014a] acknowledged that the scales of the wind dropoff are only crudely accounted by the ECMWF data. Nevertheless, the correction may be interpreted at least partially as an orographic effect because the wind deceleration bears some similarity with higher resolution ECMWF outputs (their figure 15). In the present study, the experiment run with this modified wind stress is hereafter referred to as a 'full drop-off case' (qs25 mod).

We also use the former QuikSCAT L3 product with $0.5^{\circ}$ resolution (hereafter QS50) to investigate explicitly the improvements on the upwelling dynamics allowed by the finer spatial resolution of the surface wind. The extrapolation/interpolation methodology applied to the QS50 product is the same as the one applied to QS25. The numerical experiment forced by QS50 will be noted qs50 in the following.

The model is first run for 21 years, being forced successively by a monthly climatological wind stress derived from QS50 (for the first 9 years) and QS25 (for the 12 following years). It is then run for 3 years with the daily 2005 QS25 wind stress field used in a loop. At the end of this spin up, starting from the same initial state, the three experiments qs 25 , qs 25 mod and q50 are then run in parallel. Our test experiments are one-year long and focus on the first months of 2005, a period that does not show abnormal conditions for the Benguela upwelling system (see Blamey et al. [2015), and especially their figure 10). We checked that the interpretation of the numerical results was not sensitive to the choice of the common initial state [Desbiolles et al., 2014a]. Figures 1a and 1b show the average of QS25 and QS50 wind stress, respectively, with intensities in color and directions specified by arrows over January-February 2005, i.e., a two-month period with strong upwelling-favorable winds. Only vectors for which the average intensity is higher than 0.11 $\mathrm{Pa}$ are drawn. Figure 2 shows the three meridional wind stress profiles applied on 1 January 2005 at the latitudes A (Fig. 2a) and B (Fig. 2b) specified in Fig. 1. It specially underlines two examples of the coastal modification brought on QS25, which will be discussed in section 3.2.2. Figure 3a shows the distribution of the coastal cross-shore Ekman transport in January-February 2005 
expressed as a flux (in $\left.\mathrm{m}^{2} \mathrm{~s}^{-1}\right)$ :

$T_{E}=\tau^{a} /\left(\rho_{0} f\right)$

where $\tau^{a}$ is the alongshore wind stress at the sea-land interface, $\rho_{0}$ is the seawater density and $f$ is the Coriolis parameter calculated with the $\beta$-plane approximation at $30^{\circ} \mathrm{S}$. This reference latitude is approximately in the middle of the Southern Benguela system. For each latitude, and on a daily scale, we calculate a binned Ekman transport at the first ocean grid point (in $\mathrm{m}^{2} \mathrm{~s}^{-1}$ day $^{-1}$, counted negative when directed offshore). Figure $\mathbf{3 b}$ compares the distribution of WSC for the same period over the area enclosed by a magenta frame (see Figure 1a).

The three wind stress products are mainly upwelling-favorable during the two-month period of analysis. In a previous study, we showed that the QS50 winds are less statistically related to the SST field than the QS25 winds and that the QS50 product most often overestimates the wind velocity in regions where the SST front is sharp [Desbiolles et al., 2014b]. This sensitivity to the SST front is detectable in the average wind stress structure resulting in a broader and nearer inshore atmospheric jet in the QS50 product (see Figs. 1a and 1b). Therefore, the QS50 alongshore wind stress component is associated with more Ekman transport at the coast and less upwelling-favorable WSC (i.e., negative values for the southern hemisphere) (Figs. 3a and 3b). It is worth noting that significant positive WSC patterns are observed in both QS25 and QS50 products. They mainly stem from the attenuation of the atmospheric jets that blow over the continental shelf and whose average signature is visible in Figs. 1a and 1b. Indeed, both QS25 and QS50 capture the summer atmospheric jet, noting that the finest product (QS25) shows more pronounced positive WSCs thanks to the resolution of narrower atmospheric patterns (see Fig. 3b).

The daily coastal modification brought to QS25 mod usually results in a decreased Ekman transport and an increased upwelling-favorable WSC in the coastal fringe and over the two-month period (Figs. 3a and 3b). The cross-shore length of the modification ranges from one to four ocean grid points (see the black line in Fig. 1a), i.e., about 8 to $32 \mathrm{~km}$ according to the extent of the satellite blind zone, the land-ocean mask of the model and the interpolation made on the model grid. 
For instance, the modification applied on 1 January 2005 at two specific latitudes shows an important deceleration of the wind stress over about 25 and $16 \mathrm{~km}$ off the coast for latitudes $\mathrm{A}$ and B, respectively (Fig. 2). It is worth remembering that, in the California system, the nearshore (20$25 \mathrm{~km}$ from the coast) wind modifications are mainly ascribed to orographic effects [Renault et al., 2015]. Noting that the variations in coastal orographic relief are broadly similar in the Benguela and California systems, the scale of the coastal wind modifications between QS25 and QS25 mod is assumed to represent the orography-induced drop-off length scale (hereafter $L_{\mathrm{d}}$ ).

\section{Results}

\subsection{SST, dynamical aspects and fate of coastal particles}

SST is used here as a proxy to highlight the differentiated response of the ocean to contrasted patterns in wind stress forcing. Starting from the same initial condition, and thus, with an identical thermal stratification, the SST differences between qs50 or qs $25_{\text {mod }}$ and the reference qs 25 experiment (Figure 4) underlie modifications of the dynamical and thermodynamical processes. The SST is cooler in the QS50 forcing case than in the QS25 mod case (Fig. 4b and 4c). The SST differences stem mostly from the dynamics associated with the coastal upwelling since they are weak far offshore and in the south: the modulation of coastal vertical motions by the wind stress anomalies eventually lead to the horizontal advection of colder or warmer waters (see below). This result shows that at relatively short time scales ( 2 months here), only the coastal upwelling and its underlying dynamics are affected by the change in momentum fluxes. Not surprisingly, the SST differences between qs $25_{\text {mod }}$ and qs 25 confine themselves in the nearshore region. The qs $25_{\text {mod }}$ SST is generally warmer at the coast and negative anomalies stem mostly from specific eddy patterns (Fig. 4c). It is worth noting that the qs $25_{\text {mod }}$ SST is warmer than the qs 25 SST at some well-defined retention zones (see for instance St Helena Bay, near $33^{\circ} \mathrm{S}$, Fig. 4c) [Monteiro and Roychoudhury, 2005]. 
To specify the nature of the oceanic dynamical response, we calculate the fate of the coastal Southern Benguela waters. For that purpose, we follow the trajectories of numerical tracers (particles) until they intercept one of three control sections (North, South and Offshore, see the cartoon close to Table 1) or after a maximum integration time of 6 months. The particles are initialized regularly over a coastal vertical section (along the $100 \mathrm{~m}$ isobath) for each day of January 2005. The numerical tracers are released in the whole water column, but only around the model horizontal velocity grid points where the velocity is directed toward the interior of the domain of study, i.e., with an initial velocity directed offshore. Therefore, in this study, the distribution of the initial particles gives more weight to the upper water column (where the surface wind forces an offshore Ekman flow) than to the deeper ocean (where the flow is more likely onshore). The North and South control sections approximate the northern and southern boundaries of the Southern Benguela upwelling system (see Fig. 1a) and the offshore section is set $300 \mathrm{~km}$ off the coastal section. Table 1 gives the intensity of the connection established between the coastal section and each vertical control section, and the local mean depth and age of each transfer.

For the three experiments (qs25, qs50 and qs $25_{\text {mod }}$ ), the particles are preferentially advected to the offshore and northern sections. Ekman transport and geostrophic adjustment of the upwelling front are the physical processes that explain this cross-shore and northward transport of the particles, respectively. The cross-shore transport concerns mostly the upper ocean (transfer achieved at about $15 \mathrm{~m}$ depth on average for the three experiments, see Tab. 1) and is larger in qs50

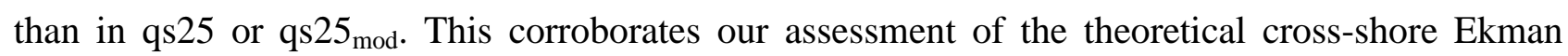
transport (Fig. 3a). Figure 5 shows the horizontal stream functions associated with the vertical integration of the cross-shore exchange calculated in the three simulations. Despite differences in transport intensity, the streamlines have an equivalent structure, with mainly a northwestward orientation. This is not surprising given that the numerical tracers are subject to the influence of both the Ekman transport in the cross-shore direction and the northward coastal jet (see next paragraph). The consistency between the overall geometry of the streamlines also suggests that the 
main upwelling cells in the Southern Benguela are located in an equivalent manner, regardless of the differences applied in the atmospheric forcing. The cross-shore exchange of particles is also characterized by numerous meanders on the stream function, confirming the mesoscale nature of the dynamics.

The northward transport consists mostly of surface waters since it is achieved at an average depth of about $30 \mathrm{~m}$ in the three experiments (see Tab. 1). Its magnitude is linked to the alongshore wind stress intensity (with, in descending order, qs 50 , qs 25 and qs $25_{\bmod }$ ). Indeed, the increased Ekman transport in qs50 leads to a cooler coastal SST (see Fig. 4), and the upwelling front is intensified. The surface coastal jet being in geostrophic balance with the SST front is also intensified: the stronger the wind stress, the cooler the SST, and the more intense the geostrophic coastal jet.

Figure 6 shows the cross-shore profile of the alongshore current (i.e., the projection of the zonal and meridional model velocity along the coast direction) as a function of depth. The 12, 13 and $14^{\circ} \mathrm{C}$ isotherms are superimposed as green dashed lines. The current is averaged along the full extension of the Southern Benguela $\left(\sim 27^{\circ} \mathrm{S}-33^{\circ} \mathrm{S}\right.$, magenta frame in Fig. 1a) and over JanuaryFebruary. The bathymetry profile also results from an average across these latitudes, and, thus, highlights the depths and distances from the coast where there is no model data. In the cross-shore direction, the strongest flow is the coastal jet in the shallow boundary layer, with an average speed greater than $10 \mathrm{~cm} / \mathrm{s}$. The $13^{\circ} \mathrm{C}$ isotherm reaches the surface in the qs50 simulation, which implies a stronger and deeper coastal jet compared to qs25 and qs25 mod (Fig. 6 and Tab.1). This echoes the findings of the Lagrangian analysis commented above. Interestingly, the subsurface dynamics are also affected, with the expansion of the poleward undercurrent in qs 25 and qs $25_{\text {mod. }}$ A poleward subsurface flow is indeed particularly strong over the continental slope off the coast in the simulations run with the highest resolution of the wind forcing (i.e., qs 25 and qs $25_{\text {mod }}$ ). This result is also confirmed by the Lagrangian diagnoses that show a transport from the coastal to the southern sections twice greater in qs 25 and qs $25_{\text {mod }}$ than in qs50 (see Tab. 1). However, the geometry of the 
experiment does not permit a clear association of this southward flow with the poleward undercurrent. Therefore, we use another Lagrangian configuration to calculate the total volume transport between the same North and South control sections, but extended to the coast. The initial particles are now regularly distributed over section North and integrated for a maximum of 6 months or till they intercept sections South or Offshore (or North in case of a northward recirculation). The North-to-South connection can be considered here as a measure of the poleward undercurrent intensity. It increases with stronger negative WSC (in ascending order, qs50, qs25 and qs $25_{\text {mod }}$; see Fig. 3b). In this new Lagrangian configuration, the volume transfers between sections North and South differ significantly $(0.01,0.04$ and $0.06 \mathrm{~Sv}$ for qs50, qs25 and qs25 mod, respectively; see Tab. 1). Sharper wind stress curl patterns in the coastal band (with essentially negative values, see Fig. 3b) allow the development of a stronger and shallower poleward undercurrent (591, 656 and 721 meters deep for qs50, qs25 and qs25 mod, respectively; see Tab. 1), as already discussed by Marchesiello et al., [2003]. This result confirms the average Eulerian description inferred from Figure 6.

\subsection{Dynamical response to a wind drop-off: Ekman Transport vs. Ekman pumping}

\subsubsection{Overall response}

To identify the contribution of the short-term signature of an orography-induced wind dropoff on upwelling dynamics along the coast, we compare qs $25_{\bmod }$ and qs 25 after only one day of parallel integration. The differences over the longer term are harder to interpret because SST anomalies can be transported away from their point of origin, which makes them unrelated to local wind contrasts. Here, long-term adjustment processes are neglected and we investigate the dynamical relationship between the alongshore wind stress and the vertical velocity response of the ocean, with anomalies expressed as differences between qs25 mod and qs25 fields on 1 January 2005.

Figure 7 shows the anomalies of the wind stress curl applied on the first day of January (red), of the SST response (blue) and of the depth-averaged vertical velocity (black), along the coastal domain 
$\left(20^{\circ} \mathrm{S}-33^{\circ} \mathrm{S}\right)$. The vertical velocity is here averaged over the upper part of the upwelling cell (i.e., from the surface to the depth of the next zero crossing). The anomalies are normalized and integrated over the zonal extension of the wind drop-off (i.e., the cross-shore distance over which wind stress curl anomalies are non-zero, $L_{\mathrm{d}}$; see below). They reflect the combined effect of the Ekman transport divergence at the coast and the integrated Ekman pumping in the cross-shore direction. Wind stress curl anomalies are not always negative (e.g., at $25.8^{\circ} \mathrm{S}$ and $30.6^{\circ} \mathrm{S}$ ) because the cross-shore variability of the ECMWF wind stress can be locally associated with intensified winds in the coastal band. At such latitudes, the following interpretation remains valid, using the QS25 wind as the drop-off case. Negative wind stress curl anomalies both decrease the cross-shore Ekman transport and increase the Ekman pumping over the scale of the wind modification $\left(L_{\mathrm{d}}\right)$. Both processes modulate the total upwelling velocities (black line in Fig. 7) and, thus, the signature in SST (blue line in Fig. 7). In general, the depth-averaged vertical velocity anomalies are well correlated negatively (positively) with the cross-shore integrated WSC anomalies (cross-shore integrated SST anomalies). A non-zero depth-averaged vertical velocity anomaly demonstrates an imbalance between Ekman pumping and Ekman transport. A wind reduction in the coastal band usually reduces the vertical upwelling velocities, which mitigates the coastal SST cooling (Fig. 7).

The combination of the two processes can be diagnosed by plotting the depth-averaged vertical velocity anomaly calculated over the first ocean grid points at each latitude as a function of the alongshore wind stress anomaly (Figure 8). The scatter plot is colored according to the SST difference between qs $25_{\text {mod }}$ and qs25: red points for differences greater than $0.1^{\circ} \mathrm{C}$, blue for differences lower than $-0.1^{\circ} \mathrm{C}$, and black for differences between -0.1 and $0.1^{\circ} \mathrm{C}$. Alongshore wind stress and vertical velocity anomalies are well correlated $(\mathrm{R}=0.68)$ with an apparent linear dependence. Positive (negative) SST anomalies correspond to negative (positive) vertical velocities and alongshore wind stress anomalies. The local vertical velocity is sensitive to the coastal wind profile (Figs. 7 and 8) and the oceanic response is immediate since the anomalies are calculated here after only one day of parallel integration. However, a large coastal and alongshore wind stress 
anomaly does not always produce a thermodynamic response in the ocean (see for instance some black points in Fig. 8). In such cases, the reduction of the Ekman transport is potentially offset by the increase of curl-driven upwelling as we shall now demonstrate.

\subsubsection{Examples of a non-systematic response}

We propose here to analyze more thoroughly the impact of the wind profile on vertical velocities and SST for latitudes where the oceanic response to an effective drop-off is contrasted. Latitudes A and B are chosen at about 27 and $29^{\circ}$ S (see Fig. 1). As suggested by Marchesiello and Estrade [2010], the competition between a reduction of coastal upwelling and an increase of Ekman pumping can be assessed by comparing the length scales of the coastal upwelling $\left(L_{\mathrm{u}}\right)$ and of the orography-induced wind drop-off $\left(L_{\mathrm{d}}\right)$.

To assess $L_{\mathrm{u}}$, we sample in the cross-shore direction the ratio $r$ between the local depthaveraged vertical velocity and the depth-averaged vertical velocity at the first ocean grid point (where the coastal upwelling is assumed to be maximal). This ratio is therefore 1 for the first ocean grid point and decreases for offshore waters. The distance from which $r$ gets close to zero is considered a proxy for $L_{\mathrm{u}}$. The calculation is presented here only for qs 25 , but we obtained the same results for qs $25_{\text {mod. }}$

Figure 9 shows this ratio $r$, the cross-shore profiles of the alongshore wind stress anomalies (i.e., differences between QS25 mod and QS25), vertical velocity anomalies, and SST anomalies at the two chosen latitudes. The characteristic length scale of the orography-induced drop-off, $L_{\mathrm{d}}$, is the cross-shore distance over which alongshore wind stress anomalies are non-zero (see Fig. 9, second row). In our model configuration, $L_{\mathrm{u}}$ ranges from one to two model grid cells, and is generally much narrower than $L_{\mathrm{d}}$ (from one to four model grid cells) (not shown). This is the case for latitude A in Fig. 9, top row. In this case, vertical velocity anomalies are negative and the resulting SST is warmer. Here, the alteration at the coast of the Ekman transport has an impact on the ocean vertical velocity field. In contrast, latitude B shows a situation in which $L_{\mathrm{u}}$ and $L_{\mathrm{d}}$ are 
equal (they both cover two ocean grid points) and the upwelling thermodynamics is insensitive to the introduction of an orography-induced wind drop-off: there are no SST or vertical velocity anomalies. These two examples are consistent with the framework proposed by Estrade et al., [2008]. They defined $L_{\mathrm{u}}$ as the length of the inner shelf zone where the bottom and surface frictional layers overlap, and thus $L_{\mathrm{u}}$ can be of the same magnitude as $L_{\mathrm{d}}$ for a broad and wide continental shelf. This is the case for our second example (B) because the $200 \mathrm{~m}$ isobath is located $200 \mathrm{~km}$ offshore whereas the same isobath is only $50 \mathrm{~km}$ offshore at latitude A (see gray line in Fig. 1b).

\section{Discussion and concluding remarks}

In this study, wind stress products available on a regular grid in space and time, resulting from the latest developments of the Ifremer team in wind retrievals, have been used to investigate the role of atmospheric fine-scales on the upwelling dynamics. Indeed, numerical experiments run in parallel from identical initial conditions helped us focus on the oceanic response to coastal wind stress structures in the Benguela upwelling system. The forcing functions applied at the surface of the ocean model differ only in the momentum fluxes. Two experiments have been run with wind stresses derived from QuikSCAT observations at two different horizontal resolutions, QS25 and QS50, corresponding to 25 and $50 \mathrm{~km}$ grids, respectively. In previous studies, we have shown that there was more spatial variability in the QS25 wind and that the missing scales in QS50 were essentially related to a poorer account of wind-SST interactions [Desbiolles et al., 2014ab]. The QS50 wind is especially overestimated in regions where the SST front is sharp (i.e., a coastal band approximately $300 \mathrm{~km}$-wide) and the WSC is better sampled by QS25 (Fig. 3b). A coastal correction has been added to the QS25 product to fill the data gap over the blind zone in the satellite coverage. This new product, QS25 mod, only differs from QS25 in a strip coastal band (8 to $32 \mathrm{~km}$ wide at most) and has been used in a third numerical experiment. This correction is considered here as an orography-induced wind drop-off that cannot be captured by scatterometry. This numerical 
experiment allows us to investigate the impact that an orography-induced coastal wind reduction would have on the coastal dynamics. We did not present the validation of the ocean model results, for instance by reference to satellite altimetry or remotely sensed SST, because our main objective is to focus on process-oriented studies for which the strict agreement with observations is not very significant. However, we could check that the regional and seasonal contrasts of the modeled sea level height bear resemblance with the variability inferred from altimetry maps. Moreover, the time evolution of the spatially averaged SST of the three simulations is in fair agreement with the observed SST seasonal variability.

The upwelling dynamics adjust quickly to a regional (QS50) or local (QS25 mod) change of the momentum fluxes. Both the offshore and northward surface flows are highly sensitive to the alteration of the alongshore wind stress component. The former sensitivity is linked to the Ekman transport and the latter to the geostrophic adjustment to the SST front. More specifically, the alongshore component of the wind stress forces the divergence of the Ekman transport at the shoreline. The resulting offshore export of surface water masses has been verified using Lagrangian calculations that follow numerical tracers initialized in the coastal area of each simulation. We calculated the stream function of the depth- and time-integrated cross-shore export. In the three experiments, the corresponding flow is mostly northwestward, with numerous meanders, and the qs50 experiment stands out for its increased Ekman transport (Fig. 5). This offshore water mass transport is compensated by upward vertical velocities at the coast and, therefore, the qs50 simulation shows the coolest coastal SST. Its $13^{\circ} \mathrm{C}$ isotherm reaches the surface, on average across the Southern Benguela subsystem, while it is found to a depth of about $20 \mathrm{~m}$ at the coast in the qs 25 and qs $25_{\text {mod }}$ simulations (see Fig. 6). This temperature difference leads to a contrasted response for the geostrophic coastal jet that results from the density front (Fig. 6). The northward transport consists mostly of surface waters and its magnitude is linked to the alongshore wind stress intensity (with, in descending order, qs50, qs 25 and qs $25_{\text {mod }}$ ).

The rest of the upwelling circulation, and especially the poleward undercurrent, is also 
sensitive to the change in wind stress forcing. We linked the intensity and the mean depth of the poleward undercurrent to the magnitude of the negative WSC in the whole coastal band, noting that this has already been done for realistic EBUS simulations (e.g., Marchesiello et al. [2003]) as well as for idealized models (e.g., Fennel and Lass [2007]). However, a thorough analysis remains to be done to determine the processes that favor the development and shallowness of the poleward undercurrent. Our results seem in line with the analytical model developed by Fennel and Lass [2007]. Their figure 6 shows the relation between the WSC and the cross-shore structure of the alongshore current: the larger the upwelling-favorable curl, the shallower and the more intense the poleward undercurrent. Fennel and Lass [2007] also discussed the significant interaction between the cross-shore structure of the currents and coastal-trapped waves (i.e., Kelvin waves in their case of a flat-bottomed coastal ocean), which is not addressed by our present study. Our Figure 6 can only suggest that the WSC favors a baroclinic coastal circulation. Marchesiello et al. [2003] showed that the vertical structure of the currents in the California system is in a Sverdrup balance. However, they analyzed long simulations forced by surface climatological fluxes. In our case, the Sverdrup balance, a dynamical equilibrium valid for long time scales, could not explain the increased southward transport in qs $25_{\text {mod. }}$ As a matter of fact, Small et al. [2015] discussed thoroughly the case of the Benguela upwelling system in a coupled ocean-atmosphere model and they showed the breaking of the Sverdrup balance when a high-resolution wind stress is used to force the ocean.

Small et al. [2015] also emphasized the need for realistic WSC patterns and a good representation of the atmospheric jet to improve the structure of the currents and the upwelling dynamics in the Benguela region, which in turn can greatly enhance the quality of the modeled SST. The cross-shore structure of the alongshore currents may have strong implications for the biogeochemical properties of the upwelled water and, thus, for the whole ecology of the Benguela upwelling system. Indeed, we found contrasted origins for upwelled particles integrated backward in time in a Lagrangian framework: the more negative the WSC, the northernmost the origin of the upwelled particles (not shown). Moreover, the shoaling of the undercurrent can favor primary 
production by increasing the subsurface nutrient reservoir [Renault et al., 2012].

Finally, the comparison between qs 25 and qs $25_{\text {mod }}$ allowed us to assess the competing effects of a decreased Ekman transport and an increased Ekman pumping. Generally, the account of an orography-induced wind drop-off leads to ocean thermodynamical anomalies: a wind reduction in the coastal band usually reduces the vertical upwelling velocities and mitigates the local SST cooling because of an imbalance between Ekman pumping and Ekman transport (Fig. 7). We found a linear dependence between the wind stress anomalies imposed at the surface and the depthaveraged vertical velocity anomalies (Fig. 8). However, we have shown that this relationship is not verified everywhere. There are some counter-examples especially at latitudes where the continental shelf is broad and with a gentle slope. More specifically, in such cases, we found that the decrease of the Ekman transport is offset by the divergence induced by the WSC. This result reflects the work of Marchesiello and Estrade [2008] because our counter-examples are characterized by equivalent length scales of the coastal upwelling $\left(L_{\mathrm{u}}\right)$ and of the orography-induced wind drop-off $\left(L_{\mathrm{d}}\right)$. Note that the way we calculate $L_{\mathrm{u}}$ may put too much weight on the model grid spacing and on the atlas used for bottom topography. Additional computations at a higher horizontal resolution would be needed to investigate thoroughly this issue. 


\section{Acknowledgments}

The authors thank two anonymous reviewers for their valuable remarks that allowed us to improve our manuscript. The authors thank D. Croizé-Fillon and the Ifremer/CERSAT team for data processing support, and are grateful to EumetSat, JPL, KNMI, and ECMWF, for providing satellite data and numerical analyses. We also thank Clément Vic for fruitful discussion on this paper. This research is supported by CNES (Centre National d'Études Spatiales), as part of the Ifesta-Up project funded by the TOSCA (Terre, Océan, Surfaces Continentales, Atmosphère) program. Support for this study has also been provided by CNES and Ifremer for FD in the form of a PhD scholarship, by the French Centre National de la Recherche Scientifique (CNRS) for BB, by Ifremer for AB and IRD (Institut de Recherche pour le Développement) for CR. 


\section{References}

Albert, A., V. Echevin, M. Lévy, and O. Aumont (2010), Impact of nearshore wind stress curl on coastal circulation and primary productivity in the Peru upwelling system, J. Geophys. Res., 115, C12033, doi:10.1029/2010JC006569.

Antonov, J. I., R. A. Locarnini, T. P. Boyer, A. V. Mishonov, and H. E. Garcia (2006), World Ocean Atlas 2005, vol. 2, Salinity, NOAA Atlas NESDIS, vol. 62, edited by S. Levitus, 182 pp., U.S. Gov. Print. Off., Washington, D. C.

Bentamy, A., and D. Croizé-Fillon (2011), Gridded surface wind fields from Metop/ASCAT measurements, Inter. J. Remote Sens, doi:10.1080/01431161.2011.600348, 1729-1754.

Bentamy, A., S. A. Grodsky, K. Katsaros, A. M. Mesta-Nuñez, B. Blanke, and F. Desbiolles (2013), Improvement in air-sea flux estimates derived from satellite observations, Inter. J. Remote Sens, doi:10.1080/01431161.2013.787502, 5243-5261.

Blamey, L. K., L. J. Shannon, J. J. Bolton, R.JM. Crawford, F. Dufois, H. Evers-King, C. L. Griffiths (2015), Ecosystem change in the southern Benguela and the underlying processes, $J$. Mar. Sys., 144, 9-29.

Blanke, B., et S. Raynaud (1997), Kinematics of the Pacific Equatorial Undercurrent: An Eulerian and Lagrangian approach from GCM results, J. Phys. Oceanogr., 27, 1038-1053.

Blanke, B., M. Arhan, S. Speich, and G. Madec (1999), Warm water paths in the equatorial Atlantic as diagnosed with a general circulation model, J. Phys. Oceanogr., 29, 2753-2768.

Blanke, B., C. Roy, P. Penven, S. Speich, J. C. McWilliams, and G. Nelson (2002), Linking wind and upwelling interannual variability in a regional model of the southern Benguela, Geophys. Res. Lett., 29, 2188, doi:10.1029/2002GL015718.

Blanke, B., S. Speich, A. Bentamy, C. Roy, and B. Sow (2005), Modeling the structure and variability of the southern Benguela upwelling using QuikSCAT wind forcing. Journal of Geophysical Research, 110, C07018, doi:10.1029/2004JC002529

Boé, J., A. Hall, F. Colas, J. C. McWilliams, X. Qu, J. Kurian, and S. B. Kapnick (2011), What 
shapes mesoscale wind anomalies in coastal upwelling zones? Clim. Dyn., 36, 2037-2049, doi:10.1007/s00382-011-1058-5.

Capet, X. J., P. Marchesiello, and J. C. McWilliams (2004), Upwelling response to coastal wind profiles, Geophys. Res. Lett., 31, L13311, doi:10.1029/2004GL020123.

Chelton, DB (1982), Large-scale response of the California Current to forcing by the wind stress curl, Calif. Coop. Fish. Rep., XXIII, 130-148.

Chelton, D. B., M. G. Schlax, M. H. Freilich, and R. F. Milliff (2004), Satellite measurements reveal persistent small-scale features in ocean winds, Science, 303, 978-983.

Chelton, D. B., M. G. Schlax, and R. M. Samelson (2007), Summertime coupling between sea surface temperature and wind stress in the California current system, J. Phys. Oceanogr., 37, 495-517.

Colas F., J. C. McWilliams, X. Capet, and J. Kurian (2012), Heat balance and eddies in the PeruChile current system, Clim. Dyn., 39, 1-2, 509-529.

Desbiolles, F., B. Blanke, and A. Bentamy (2014a), Short-term upwelling events at the western African coast related to synoptic atmospheric structures as derived from satellite observations, J. Geophys. Res. Oceans, 119, doi:10.1002/2014JC010015.

Desbiolles, F., B. Blanke, A. Bentamy, and N. Grima (2014b), Origin of the wind stress curl structures in the Benguela and Canary Upwelling systems, J. Geophys. Res. Oceans, 119, 461-483, doi:10.1002/2013JC009278.

Edwards, K. A., A. M. Rogerson, C. D. Winant, and D. P. Rogers (2001), Adjustment of the marine atmospheric boundary layer to a coastal cape. Journal of the Atmospheric Sciences, 58 (12), $1511-1528$

Estrade P., P. Marchesiello, A. Colin de Verdiere, and C. Roy (2008), Cross-shelf structure of coastal upwelling: a two-dimensional expansion of Ekman's theory and a mechanism for innershelf upwelling shut down. J. Mar. Res., 66, 589-616.

Fennel, W., and H.U. Lass (2007), On the impact of wind curls on coastal currents. Journal of 
Marine Systems, 68(1), 128-142.

Fennel, W., T. Junker, M. Schmidt, and V. Mohrholz (2012), Response of the Benguela upwelling systems to spatial variations in the wind stress. Contin. Shelf. Res., 45, 65-67.

Hutchings L., M. Barange, S. F. Bloomer, A. J. Boyd, R. J. M. Crawford, J. A. Hugget, M. Kerstan, J. L. Korrubel, J. A. A. De Oliviera, S. J. Painting, A. J. Richardson, L. J. Shannon, F. H. Schulein, C. D. Van de Lingen, and H. M. Verheye (1998), Multiple factors affecting South African anchovy recruitment in the spawning, transport and nursery areas. In: Benguela Dynamics: Impacts of variability on shelf-sea environments and their living resources. Pillar, S. C., Moloney, C., Payne, A. I. L. and F. A. Shillington (Eds). S. Afr. J. Mar. Sci., 19, 211-225.

JPL (2006), QuikSCAT science data product user's manual (version 3.0), Jet Propulsion Laboratory Publ. D-18053, Pasadena, CA, 91 pp., available online: http://podaac.jpl.nasa.gov/DATA CATALOG, 2006.

Locarnini, R. A., A. V. Mishonov, J. I. Antonov, T. P. Boyer, and H. E. Garcia, 2006: World Ocean Atlas 2005, vol. 1, Temperature, NOAA Atlas NESDIS, vol. 61, edited by S. Levitus, 182 pp., U.S. Gov. Print. Off., Washington, D. C.

Marchesiello P, J. C. McWilliams, and A. Shchepetkin (2003), Equilibrium structure and dynamics of the California current system, J. Phys. Oceanogr., 33, 753-783.

Marchesiello, P., and P. Estrade (2010), Upwelling limitation by geostrophic onshore flow, J. Mar. Res., 68, 37-62, doi:10.1357/002224010793079004.

Monteiro, P. M., and A. N. Roychoudhury (2005). Spatial characteristics of sediment trace metals in an eastern boundary upwelling retention area (St. Helena Bay, South Africa): A hydrodynamic-biological pump hypothesis. Estuarine, Coastal and Shelf Science, 65(1), 123134.

O’Neill, L. W., D. B. Chelton, S. K. Esbensen, and F. J. Wentz (2005), High-resolution satellite observations of SST modification of the marine atmospheric boundary layer over the Agulhas Return Current, J. Climate, 18, 2706-2723. 
Perlin, N., E. D. Skllingstad, R. M. Samelson, and P. L. Barbour (2007), Numerical simulation of air-sea coupling during coastal upwelling, J. Phys. Oceanogr., 37, 2081-2093

Perlin, N., E. D. Skyllingstad, and R. M. Samelson (2011), Coastal atmospheric circulation around an idealized cape during wind-driven upwelling studied from a coupled ocean-atmosphere model, Mon. Wea. Rev., 139, 809-829.

Renault, L., B. Dewitte, M. Falvey, R. Garreaud, V. Echevin, and F. Bonjean (2009), Impact of atmospheric coastal jet off central Chile on sea surface temperature from satellite observation (2000-2007), J. Geophys. Res., 114, C08006, doi:10.1029/2008JC005053.

Renault, L., B. Dewitte, P. Marchesiello, S. Illig, V. Echevin, G. Cambon, M. Ramos, O. Astudillo, P. Minnis, and J. K. Ayers (2012), Upwelling response to atmospheric coastal jets off central Chile: A modeling study of the October 2000 event, J. Geophys. Res., 117, C02030, doi:10.1029/2011JC007446.

Renault, L., A. Hall, and J. C. McWilliams (2015), Orographic shaping of U.S. West Coast wind profiles during the upwelling season, Clim. Dyn., in revision.

Rykaczewski, R. R., and DM Checkley (2008), Influence of ocean winds on the pelagic ecosystem in upwelling regions, Proc. Natl. Acad. Sci. U.S.A., 105, 1965-1970.

Shchepetkin, A. F., and J. C. McWilliams (2005), The regional oceanic modeling system (ROMS): A split-explicit, free-surface, topography following-coordinate oceanic model, Ocean Modell., 9, 347-404, doi:10.1016/j.ocemod.2004.08.002.

Shchepetkin, A. F., and J. C. McWilliams (2009), Correction and commentary for "Ocean forecasting in terrain-following coordinates: Formulation and skill assessment of the regional ocean modeling system" by Haidvogel et al., J. Comput. Phys., 227, 3595-3624.

Small, R. J., S. P. deSzoeke, S. P. Xie, L. O’Neill, H. Seo, Q. Song, P. Cornillon, M. Spall, and S. Minobe (2008), Air-sea interaction over ocean fronts and eddies, Dyn. Atm. Ocean., 45, 274319.

Small, R. J., E. Curchistern, K. Hedstrom, B. Kauffman, and W. Large (2015), The Benguela 
upwelling system: Quantifying the sensitivity to resolution and coastal wind representation in a global climate model, J. Climate, in revision.

Smith, W. H. F., and D. T. Sandwell (1997), Global seafloor topography from satellite altimetry and ship depth soundings, Science, 277, 1956-1962, doi:10.1126/science.277.5334.1956.

Song, Q, D. B. Chelton, S. K. Esbensen, N. Thum, and L. W. O’Neil (2009), Coupling between seasurface temperature and low-level winds in mesoscale numerical models, J. Climate, 22, 146164.

Stiles, B. (2014), Discovering a decade of coastal winds from scatterometers. International Ocean Vector Wind Science Team Meeting, 2-4 June 2014, Brest, France. 
(a) QS25

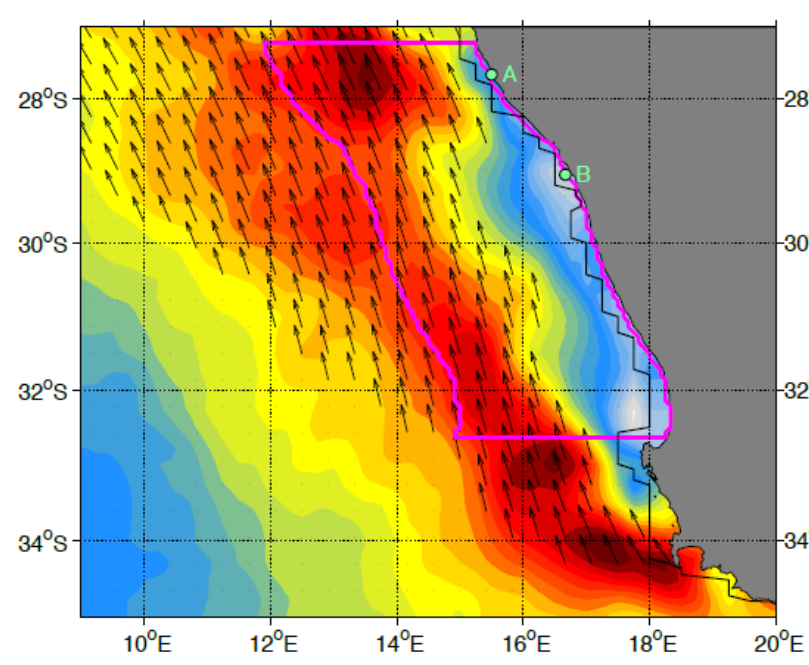

(b) QS50

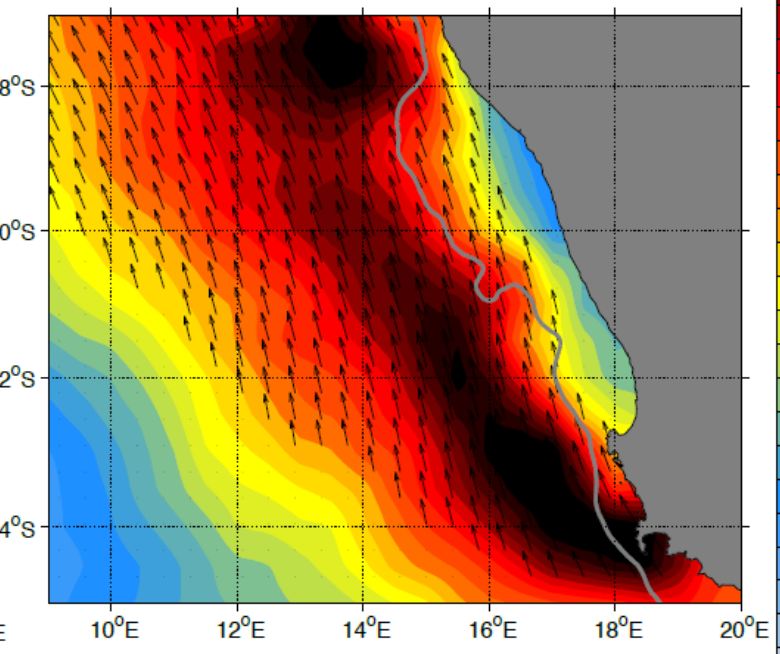

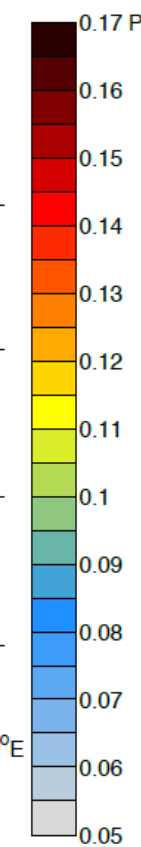

Fig. 1 
(a) Latitude $\mathrm{A}\left(\sim 27.6^{\circ} \mathrm{S}\right)$

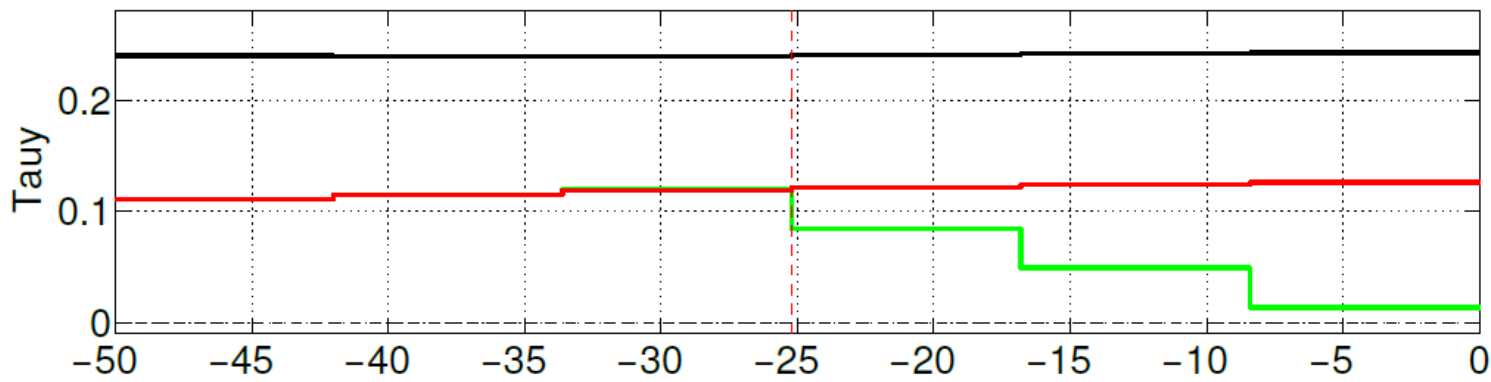

(b) Latitude B ( 29S)

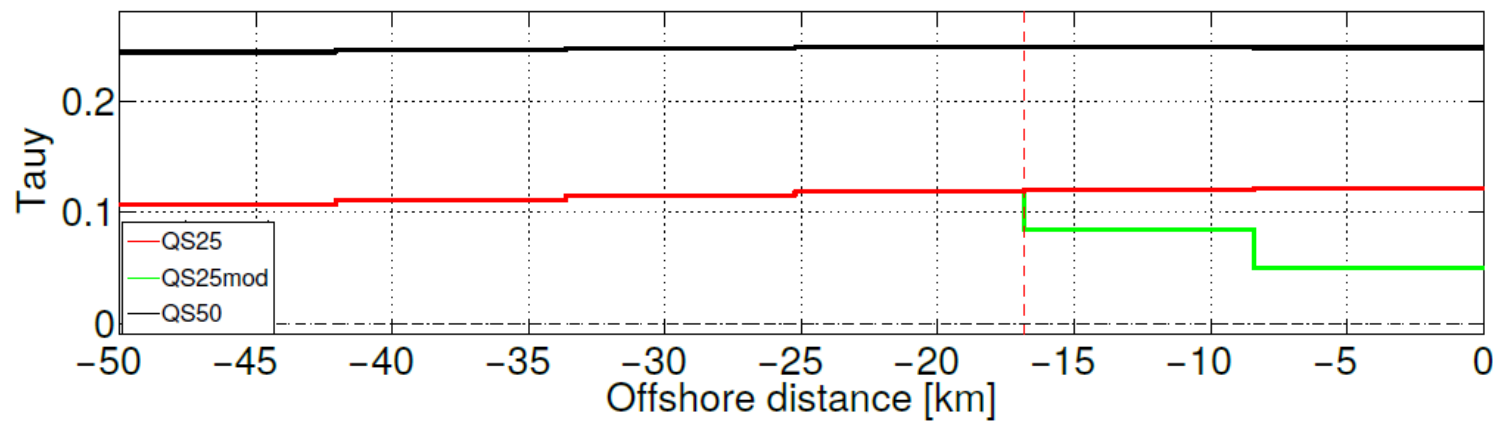

Fig. 2 
(a)

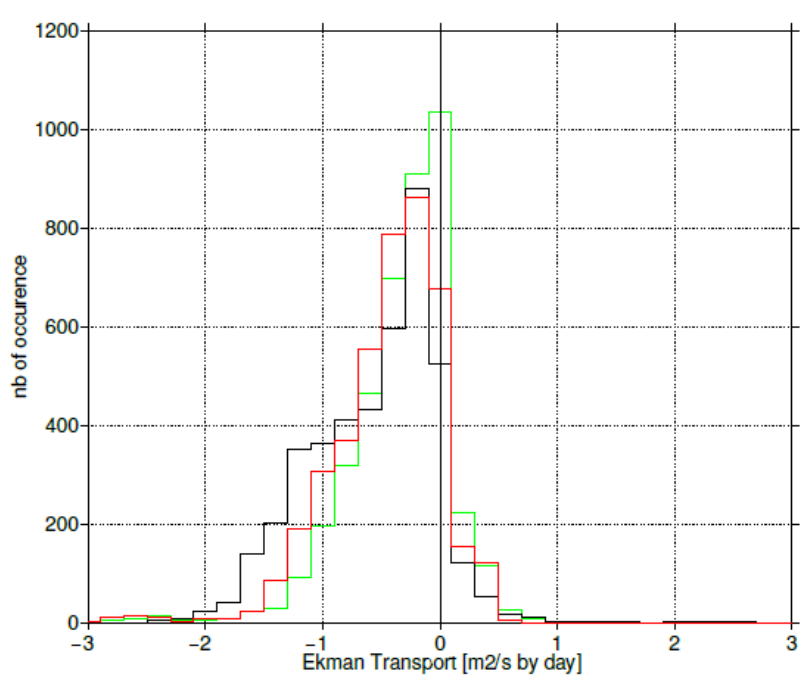

(b)

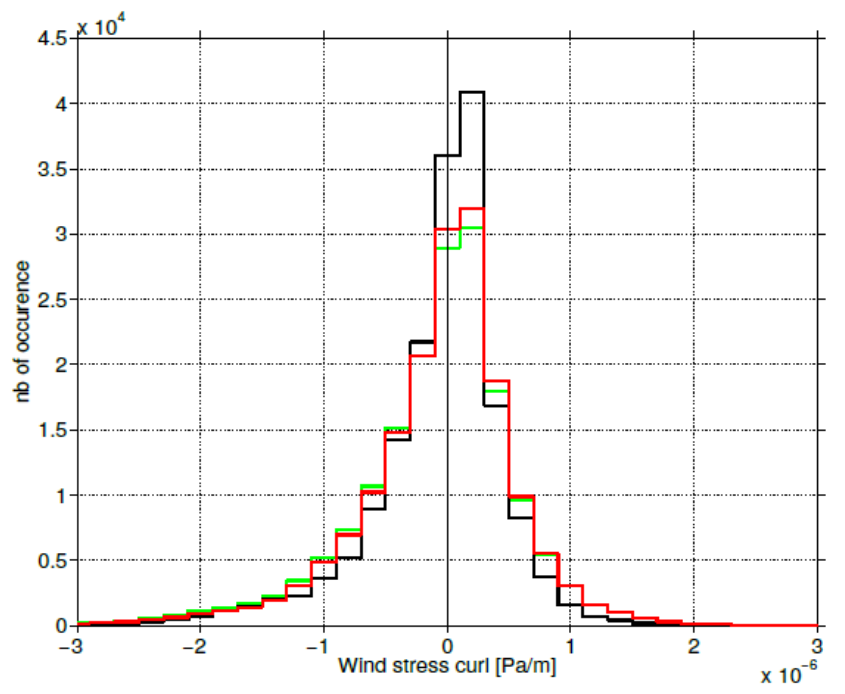

Fig. 3 
(a) qs25

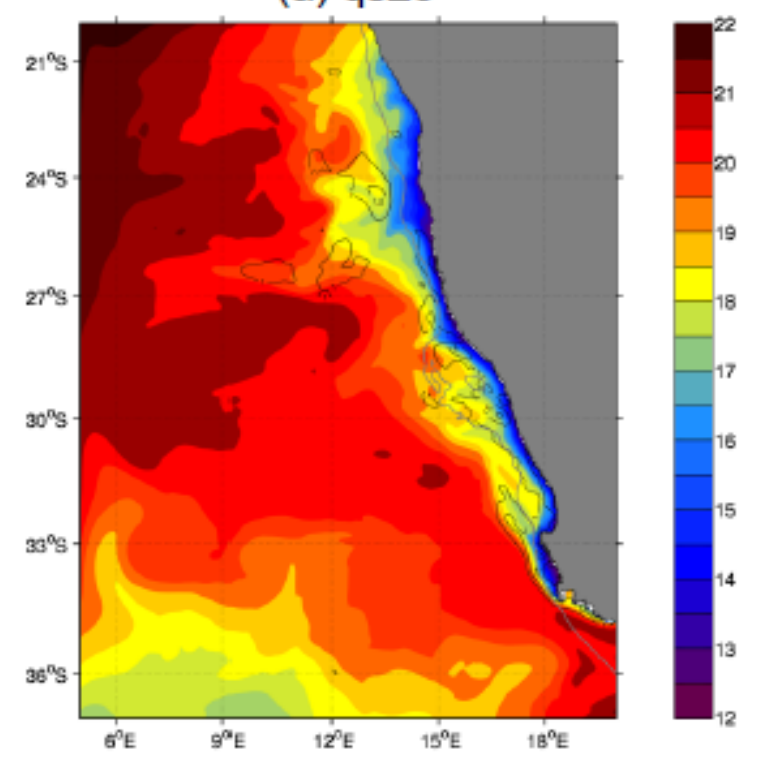

(b) qs50 - qs25

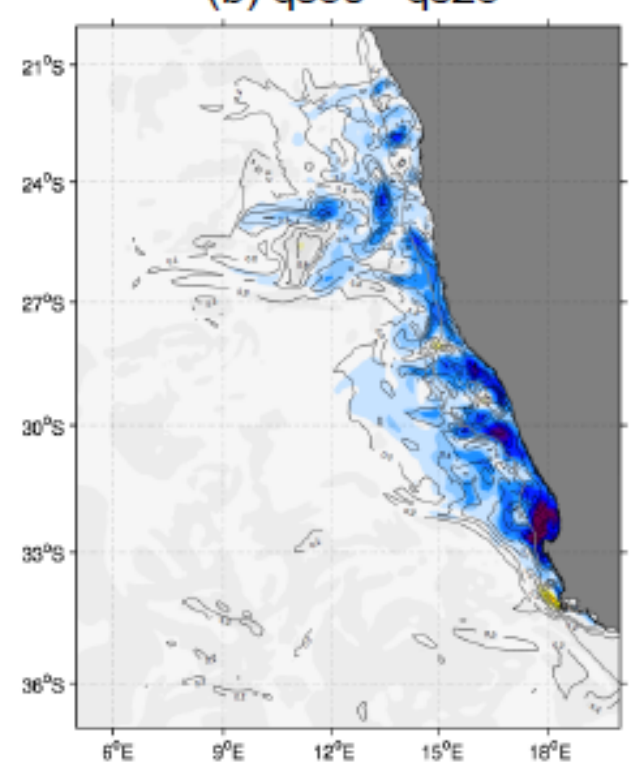

(c) qs $25_{\bmod }$ - qs25
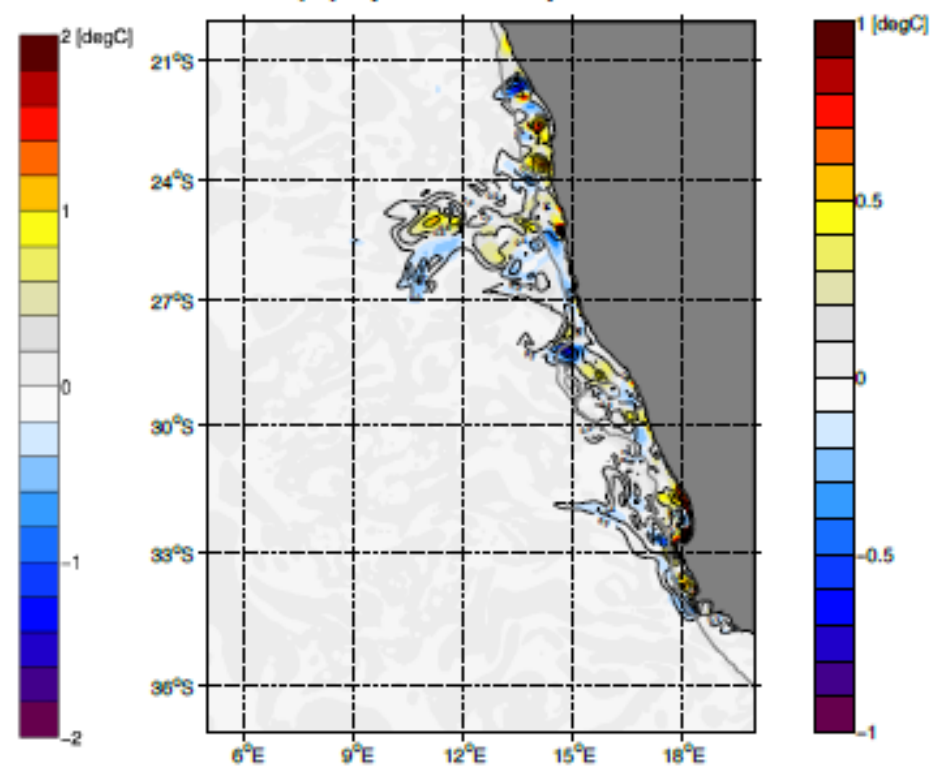

Fig. 4 
(a) qs25

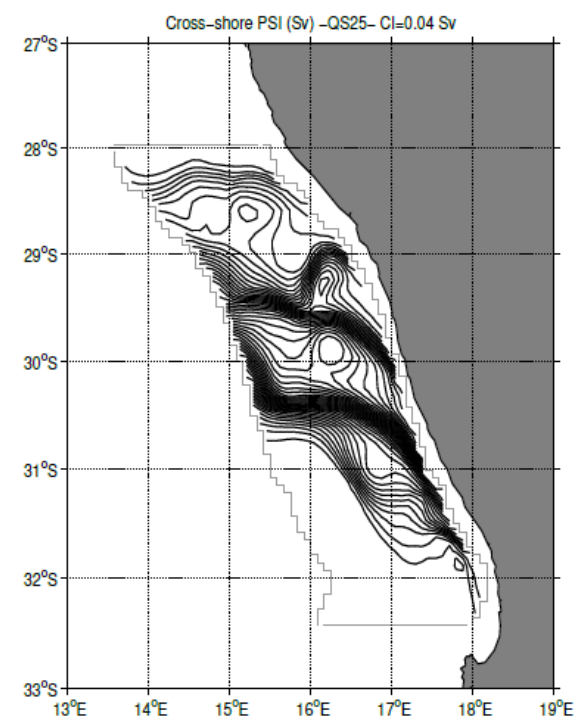

(b) qs25 mod

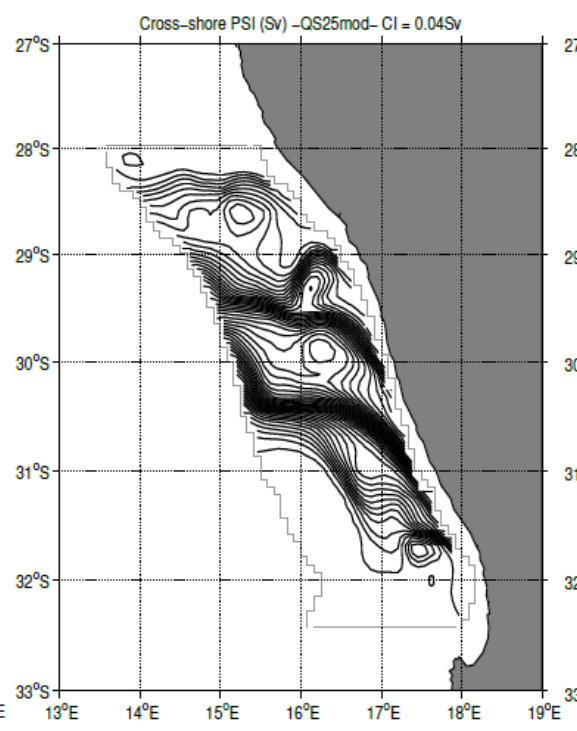

(c) $q s 50$

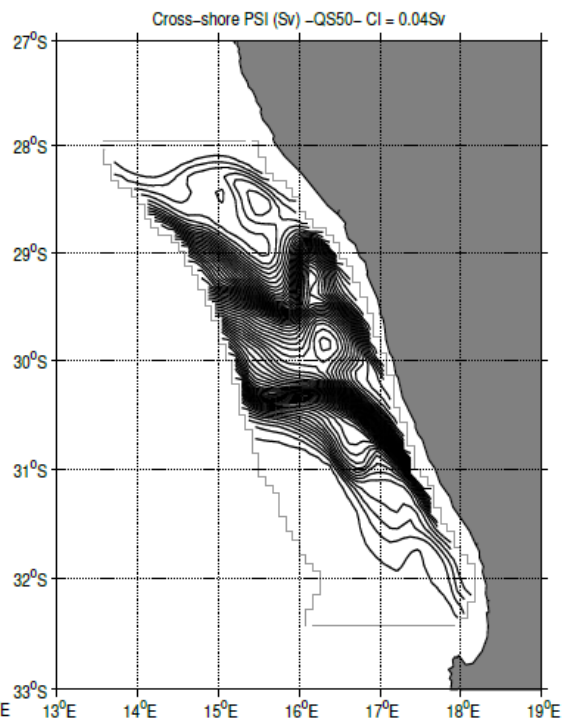

Fig. 5 
(a) qs 25

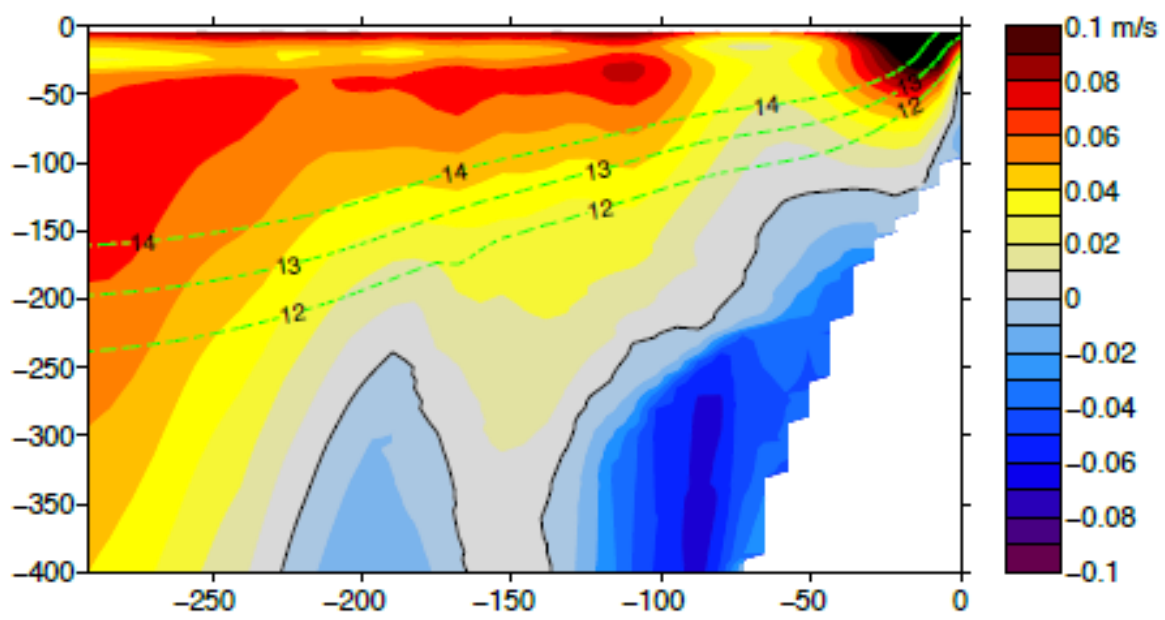

(b) $q s 25_{\bmod }$

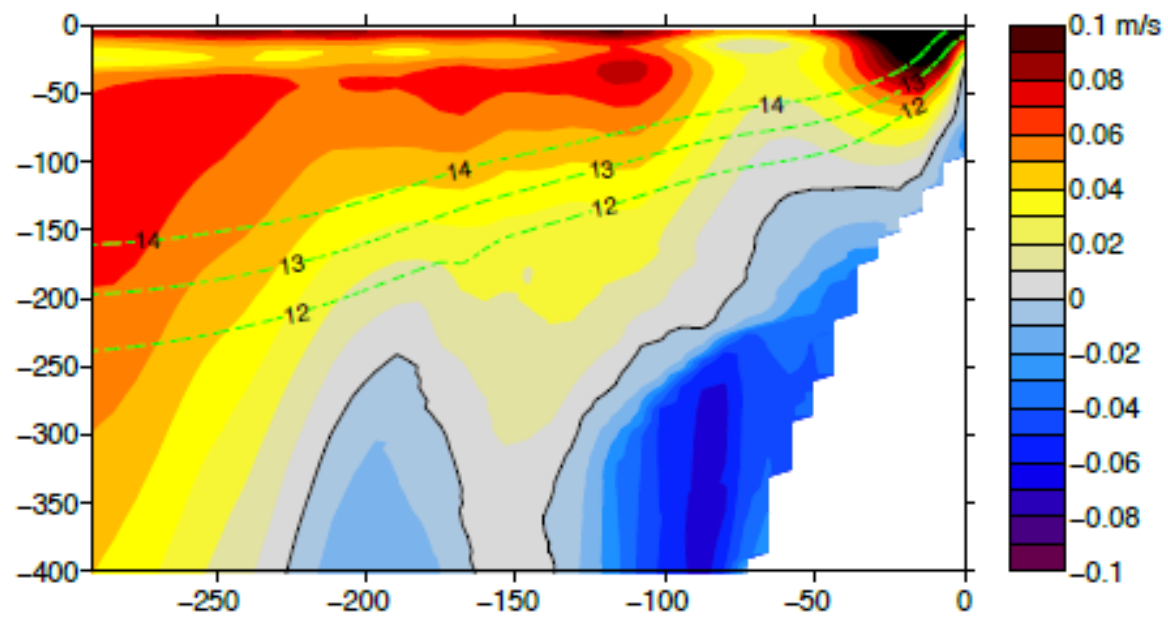

(c) qs50

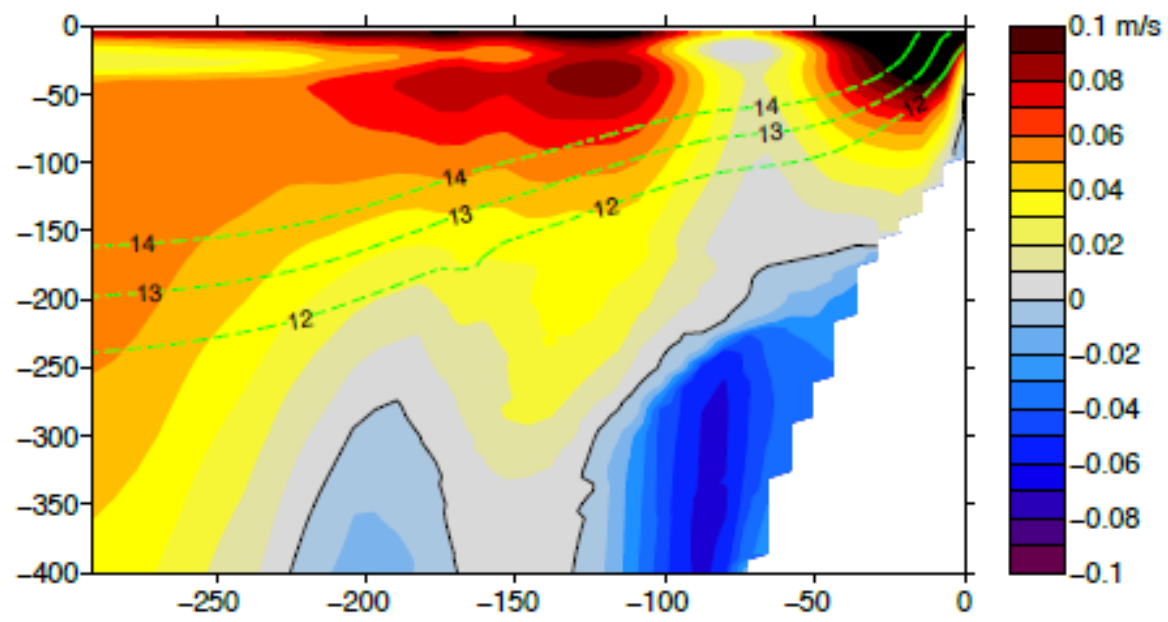

Fig. 6 


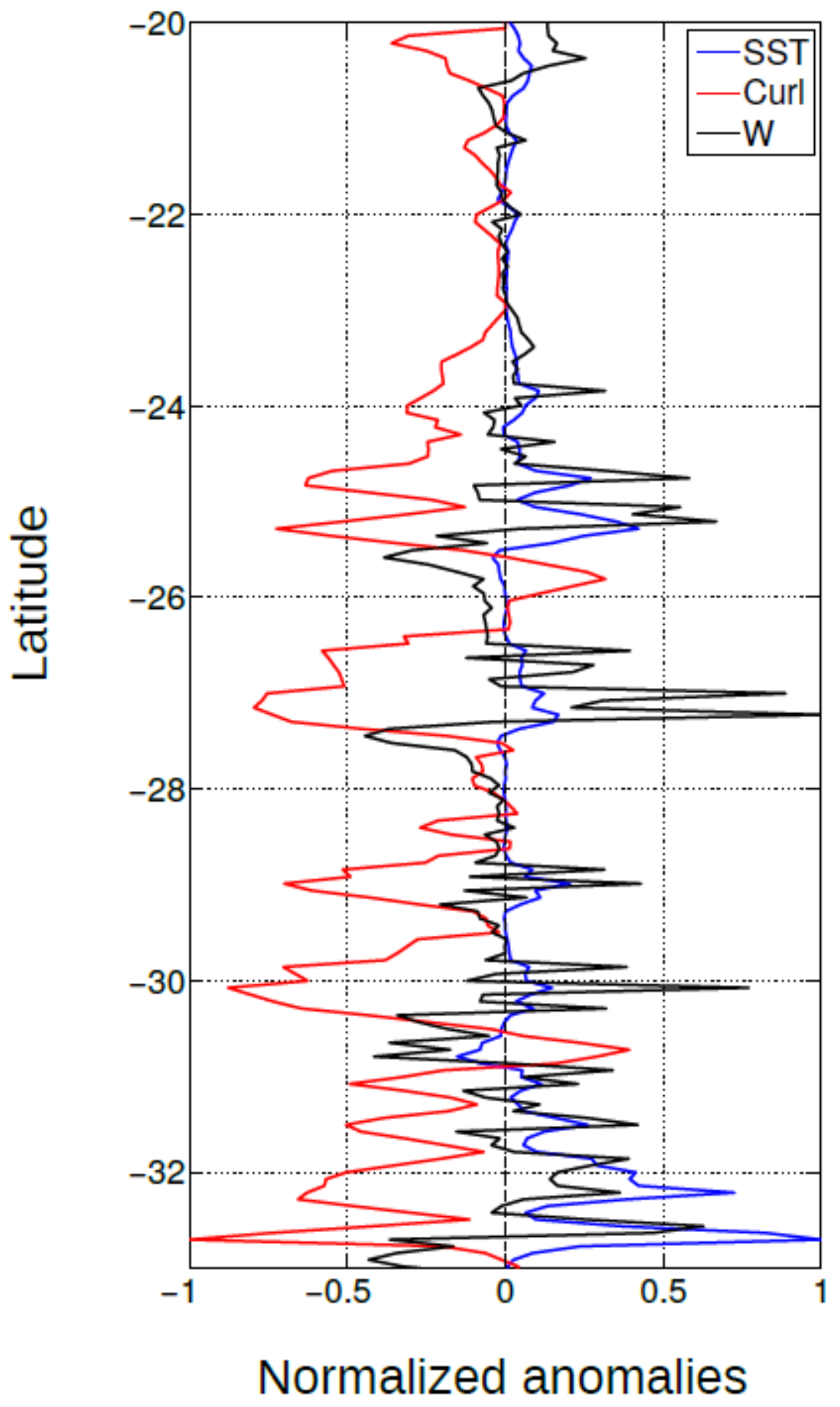

Fig. 7 


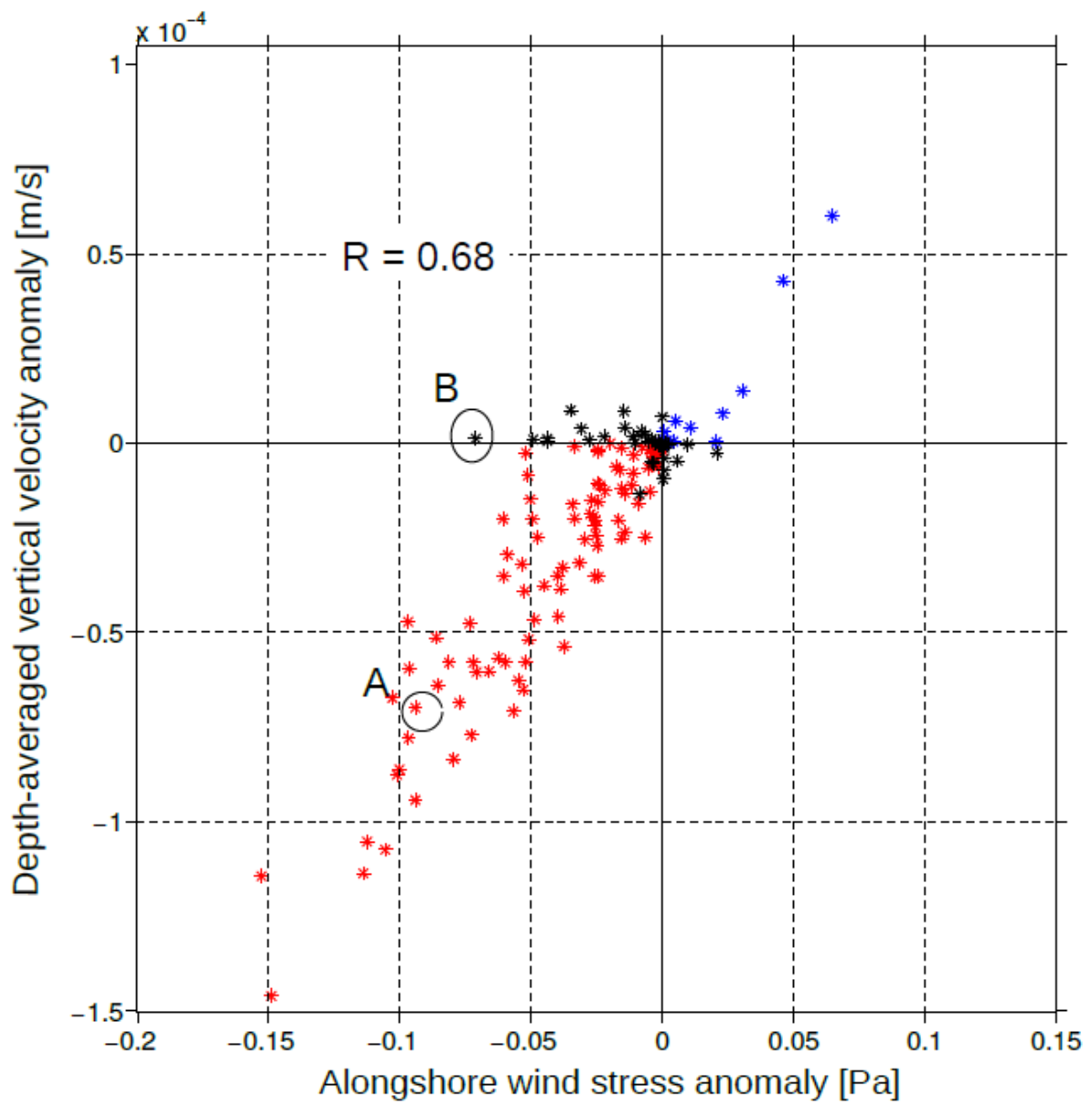

Fig. 8 
Unbalanced processes
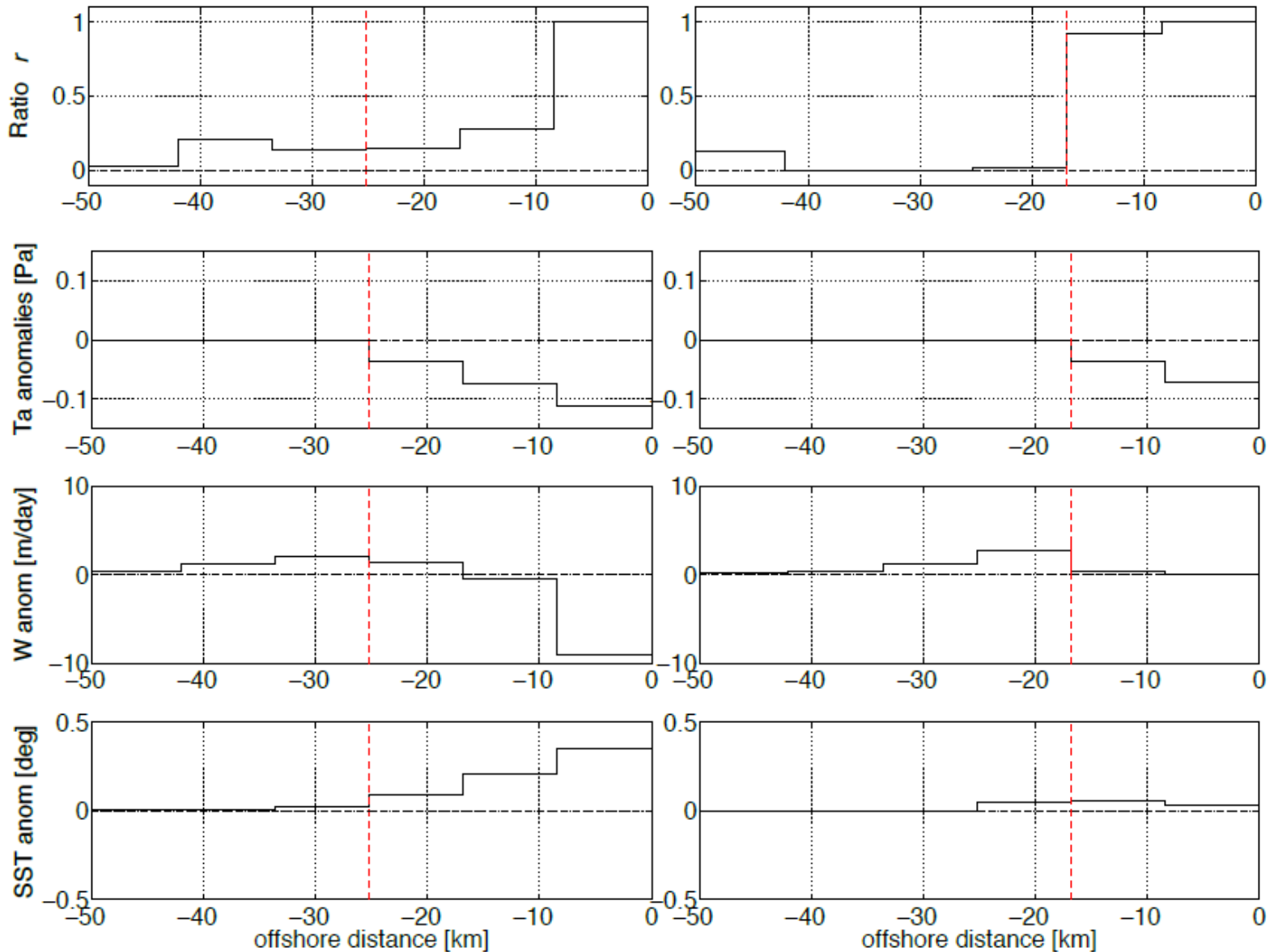

(a)

(b)

Fig. 9 


\section{Table and figure caption}

Table 1: Total transport, mean depth and age of the particles transported from the coastal section (green line) to one of the three control sections (North, South and Offshore), and total northto-south transport, mean depth and age of the particles. Numbers between brackets indicate the standard deviation.

Figure 1: Average QS25 (a) and QS50 (b) wind stress intensity (colors) and direction (arrows) over the main upwelling season (January-February 2005). Only vectors for which the average intensity is higher than $0.11 \mathrm{~Pa}$ are drawn in both cases. Locations $\mathrm{A}$ and B identify the latitudes chosen as examples for the wind profiles shown in Fig. 2 and for the cross shore profiles proposed in Fig. 9. In (a), the black line delimits the coastal zone over which the QS25mod modifications are done, and the magenta frame highlights the Southern Benguela domain used in Figs. 3b and 6, and for the Lagrangian experiments (see text for more details). The gray line in (b) is the $200 \mathrm{~m}$ isobath.

Figure 2: QS25 (red), QS25 mod (green) and QS50 (black) wind stress profiles on 1 January 2005 for the latitudes A (a) and B (b) specified in Fig. 1.

Figure 3: (a) Distribution of the January-February 2005 Ekman transport expressed as a flux and calculated with the QS25 (red), QS25mod (green) and QS50 (black) alongshore wind stress component (see text for more details). (b) Distribution of the January-February 2005 WSC over the magenta frame drawn in Figure 1a calculated with the QS25 (red), QS25 mod (green) and QS50 (black) wind stress field. 
Figure 4: (a) Mean (colors) and standard deviation (contours) of the January-February 2005 SST in the reference run (qs25). (b) Mean SST bias between qs50 and qs25 over the same period (c) Mean SST bias between qs $25_{\text {mod }}$ and qs 25 over the same period.

Figure 5: Horizontal stream functions associated with the vertical and temporal integration of the cross-shore exchange calculated with the advection of numerical tracers in (a) qs25, (b) qs $25_{\text {mod }}$ and (c) qs50.

Figure 6: Cross-shore profile of the alongshore current (i.e., the projection of the zonal and meridional model velocity along the coast direction) as a function of depth for (a) qs25, (b) qs $25_{\text {mod }}$ and (c) qs50. The 12,13 and $14^{\circ} \mathrm{C}$ isotherms are superimposed as green dashed lines. The current is averaged along the full extension of the Southern Benguela $\left(\sim 27^{\circ} \mathrm{S}-33^{\circ} \mathrm{S}\right.$, magenta frame in Fig. 1a) and over January-February.

Figure 7: Wind stress curl anomalies applied on the first day of January (red), SST anomalies (blue) and depth-averaged vertical velocity (black), along the coastal domain $\left(20^{\circ} \mathrm{S}-33^{\circ} \mathrm{S}\right)$. The vertical velocity is averaged over the upper part of the upwelling cell (i.e., from the surface to the depth of the next zero crossing). The anomalies are normalized and integrated over the zonal extension of the wind drop-off (see text for more details).

Figure 8: Depth-averaged vertical velocity anomalies (calculated over the first ocean grid points at each latitude) as a function of the alongshore wind stress anomalies. The scatter plot is colored according to the SST difference between $\mathrm{qs} 25_{\text {mod }}$ and qs25: in red for differences greater than $0.1{ }^{\circ} \mathrm{C}$, blue for differences lower than $-0.1^{\circ} \mathrm{C}$, and black for differences between 0.1 and $0.1^{\circ} \mathrm{C}$. 
Figure 9: Cross-shore profiles of ratio $r$ (top row, see text for more details), alongshore wind stress anomalies (second row), vertical velocity anomalies (third row) and SST anomalies (bottom row) at the two chosen latitudes A and B specified in Figs. 1 and 8.

Table 1: Total transport, mean depth and age of the particles transported from the coastal section (green line) to one of the three control sections (North, South and Offshore), and total north-tosouth transport, mean depth and age of the particles. Numbers between brackets indicate the standard deviation.

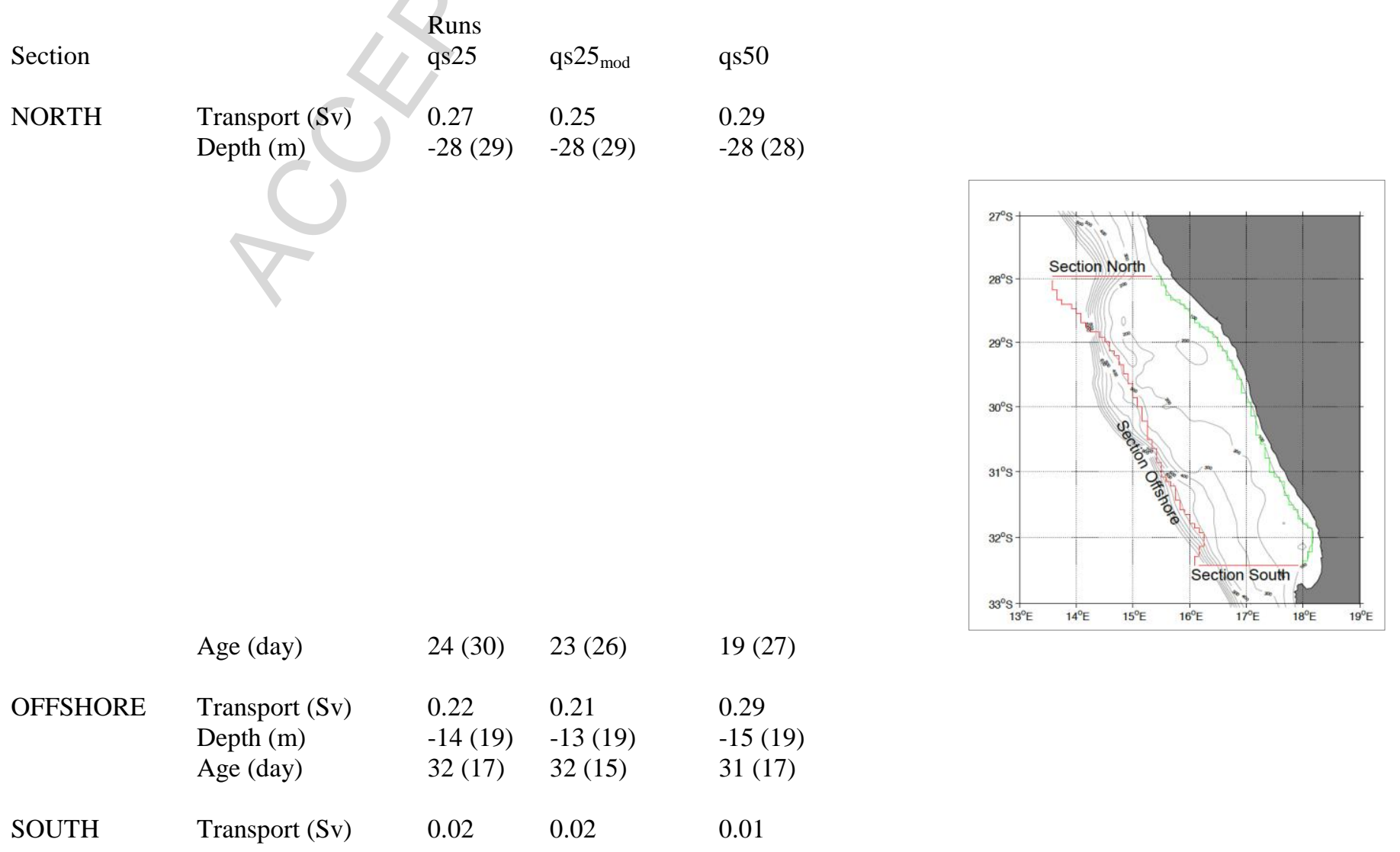




$\begin{array}{llll}\text { Depth }(\mathrm{m}) & -122(54) & -150(74) & -122(57) \\ \text { Age (day) } & 61(54) & 70(61) & 62(57)\end{array}$

NORTH-TO- Transport (Sv)

0.04

0.06

0.01 SOUTH

$\begin{array}{llll}\text { Depth }(\mathrm{m}) & -656 & -591(232) & -721(150) \\ & (159) & & \\ \text { Age (day) } & 124(14) & 124(12) & 139(16)\end{array}$

